\title{
ULTRASONOGRAM-GUIDED FINE NEEDLE ASPIRATION CYTOLOGY IN MEDIASTINUM AND LUNG LESIONS
}

\author{
V. Senthilvelmurugan ${ }^{1}$, A. Premalatha ${ }^{2}$ \\ 1 Professor and HOD, Department of Radiology, KAPV Government Medical College, Trichy. \\ ${ }^{2}$ Assistant Professor, Department of Pathology, KAPV Government Medical College, Trichy.
}

\section{ABSTRACT}

\section{BACKGROUND}

Percutaneous fine needle aspiration cytology is a simple and safe method of diagnosing various intrathoracic lesions. CT and sonography are newer methods of guidance for aspiration cytology. This study was undertaken to assess the role of ultrasonography in guiding 23/24 gauge needle without local anaesthesia for aspiration cytology of lung and mediastinal lesions. The diagnosis was correlated with histopathology reports. Complications following the procedure were also evaluated.

\section{MATERIALS AND METHODS}

69 patients with intrathoracic lesions (lung/mediastinal/pleural) suspected to be neoplastic were recruited for the study. Fibreoptic bronchoscopy was performed and biopsy with histopathological examination was undertaken after obtaining informed consent from the patients. A record of history, clinical diagnosis, chest radiograph, ultrasonography, CT scan and FNAC diagnosis, complications, final diagnosis and followup was maintained.

\section{RESULTS}

53.6\% cases were in the fourth to fifth decade. Majority of patients [47 (68.1\%)] presented with pulmonary mass/unresolving pneumonia, 11 (15.9\%) presented with mediastinal widening/mass and $3(4.3 \%)$ presented with pleural effusion. 69 patients underwent guided FNAC. One patient (1.4\%) of carcinoma bronchus with malignant effusion developed minimal pneumothorax after the procedure. No other complications were reported. The aspiration results of seven patients were unsatisfactory and no opinion could be given. Fourteen were nonmalignant lesions of which one was neoplastic and rest ( $n=13)$ were inflammatory/infectious conditions and 48 patients were found to have malignant lesions. The same results were obtained on histopathological correlation.

\section{CONCLUSION}

Ultrasonographically guided fine needle aspiration cytology of pulmonary, mediastinal and pleural masses is significantly faster than other modalities and yielded results in a high percentage of cases, even when the target lesion was small.

\section{KEYWORDS}

Ultrasonogram Guidance, Fine Needle Aspiration Cytology, Mediastinal Mass, Histopathology.

HOW TO CITE THIS ARTICLE: Senthilvelmurugan V, Premalatha A. Ultrasonogram-guided fine needle aspiration cytology in mediastinum and lung lesions. J. Evolution Med. Dent. Sci. 2016;5(84):6282-6286, DOI: 10.14260/jemds/2016/1419

\section{BACKGROUND}

Percutaneous fine needle aspiration cytology is a relatively simple, safe and efficacious means of diagnosing benign, malignant and inflammatory lesions of lung mediastinum and pleura. $^{1-3}$

Imaging-guided percutaneous transthoracic biopsy has become an effective and widely accepted minimally invasive technique for diagnosis of a variety of intrathoracic lesions not readily accessible with bronchoscopy. ${ }^{4}$

Aspiration biopsy of small and large lesions of lung and mediastinum may provide an early diagnosis, thus enabling effective intervention and increasing the potential of surgical care. Cytopathological evaluation has contributed a lot to the diagnosis even in the presence of minimal biopsy tissue. The

Financial or Other, Competing Interest: None.

Submission 07-09-2016, Peer Review 07-10-2016,

Acceptance 13-10-2016, Published 20-10-2016.

Corresponding Author:

Dr. V. Senthilvelmurugan,

22/B-23, Subham Gardens,

Srinivasa Nagar, $6^{\text {th }}$ Main Road,

Trichy-17.

E-mail: drsvmrd@gmail.com

DOI: $10.14260 /$ jemds/2016/1419

\section{(c) $($ ) $९$}

advent of new technology like fluoroscopy, ultrasonography, and CT scan provide documentation of the needle in the mass lesion. ${ }^{3,5,6}$

Ultrasonography (USG) is gaining acceptance as an effective guidance modality, even for difficult and small intrathoracic lesions. Several recently published articles have illustrated the role of ultrasonography as the "undiscovered jewel of interventional radiology". Ultrasonography is an effective and safe alternative to CT for guidance at biopsy of masses abutting the chest wall. Real-time USG visualisation allows accurate needle placement, shorter procedure time and better performance in debilitated and less cooperative patients. ${ }^{4}$

The present study was undertaken to assess the role of USG in guiding 23/24 gauge needle without local anaesthesia for aspiration cytology of lung and mediastinal lesions. The utility of $23 / 24$ gauge needle in diagnosis was evaluated by correlating with histopathology reports wherever possible. The incidence of complications following ultrasonographyguided fine needle aspiration was also evaluated.

\section{MATERIALS AND METHODS}

This prospective study comprised of 69 patients with intrathoracic lesions (lung/mediastinal/pleural) referred to 
the Department of Radiodiagnosis for fine needle aspiration under USG guidance. The patients included in this study were clinically suspected to have a neoplasm as evidenced by pulmonary opacities or nodules adjacent to the chest wall, masses of mediastinum or chest wall or pleural diseases. Fibreoptic bronchoscopy was performed and a biopsy was taken whenever possible.

\section{Inclusion Criteria}

- Undiagnosed lung or mediastinal lesions with symptoms of cough, fever and/or haemoptysis, a previous history of malignancy or immune deficiency in a patient who presents with one or more lung lesions.

- Lung or mediastinal lesions discovered incidentally in a totally asymptomatic patient.

- $\quad$ Patients with unresolving pneumonia.

\section{Exclusion Criteria}

- Non-consent.

- Suspected vascular lesion.

- Suspected hydatid disease.

- Patients needing assisted ventilation.

- Severe pulmonary hypertension.

- COPD with bullae documented by radiograph.

A systematic record of history, clinical diagnosis, chest radiograph diagnosis, ultrasonographic findings, CT scan findings, FNAC diagnosis, complications, final diagnosis and followup was maintained in a proforma prepared for this purpose.

Fine needle aspirations were performed after reasonable radiographic localisation of the lesion initially by means of postero-anterior and lateral radiographs of the chest, followed by ultrasonographic guidance. Hospitalisation was not considered essential prior to the procedure. All aspirations were performed after obtaining informed consent without any premedication or anaesthesia, irrespective of size or depth of the lesion or of the age of the patient. Patients were given various breathing instructions depending on the location of the lesion, to enable optimal visibility. Scans were obtained with the patient in the supine and prone decubitus.

Ultrasonographic examination was done using the real time sonographic unit (Model RT-3600, GE Medical systems) with a sector -electronic -array transducer of $3.5 \mathrm{MHz}$. After application of a coupling medium, the scanner was placed over the area to be examined and longitudinal and transverse scans were obtained. The liver and gallbladder were used as tissue texture reference for solid and fluid containing region. Normal areas were scanned as a control.

After these preliminary evaluations, skin was cleaned to ensure strict aseptic precaution for FNAC. Distances from the skin to anterior and posterior surfaces of the mass or lesion were measured through the overlying rib interspace. Under strict aseptic precautions, a disposable 23 or 24 gauge needle was inserted into the lesion during suspended respiration under real-time visualisation. After the needle tip was confirmed to be in the desired lesion, aspiration was performed during continuous observation of the position of the needle tip to ensure that needle excursions were limited to the lesion.
The needle tip was seen as a white spot or small linear echogenicity. In large lesions, the periphery of the mass or areas deemed less necrotic on the basis of their ultrasound appearance were specifically targeted.

The aspirated material was expelled onto a glass slide, smeared and fixed in 95\% ethyl alcohol. The smear was stained by Papanicolaou's or May-Grunwald-Giemsa stain and examined in cytology department.

At the completion of the procedure, all patients underwent expiratory chest radiography to detect a pneumothorax and all outpatients were monitored for 1-2 hours in the recovery area. Positional restrictions were observed in all patients to decrease the risk of post-procedural pneumothorax. The patient was asked to return to the hospital in case he or she had severe chest pain, haemoptysis or breathlessness. In cases where the first FNAC report was unsatisfactory, a repeat FNAC was advised.

\section{RESULTS}

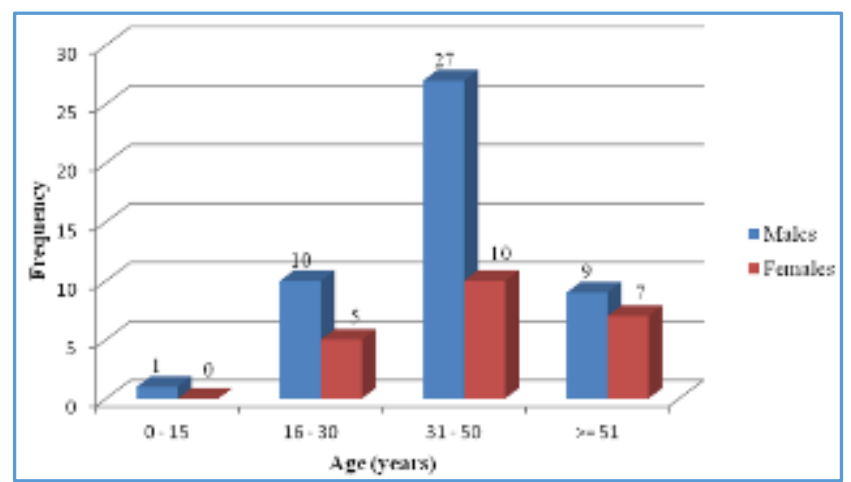

Figure 1. Patient Demographics

The majority of patients $(n=37,53.6 \%)$ were in the age group of 31 to 50 years. Of the 69 cases, $47(68.1 \%$ ) were males and $22(31.9 \%)$ were females. The male to female ratio was 2.6:1. The youngest patient was a 6-month-old boy and the oldest being a 66-year-old male. [Figure 1]

\begin{tabular}{|c|c|}
\hline Presentation & N (\%) \\
\hline $\begin{array}{c}\text { Pulmonary mass lesions/unresolving } \\
\text { pneumonia }\end{array}$ & $47(68.1)$ \\
\hline Mediastinal mass/widening & $11(15.9)$ \\
\hline Superior Vena Cava Obstruction & $3(4.3)$ \\
\hline Pleural effusion & $3(4.3)$ \\
\hline $\begin{array}{c}\text { Thyroid masses with retrosternal } \\
\text { extension }\end{array}$ & $1(1.5)$ \\
\hline Synovial sarcoma with lung secondaries & $1(1.5)$ \\
\hline Carcinoma cervix with lung secondaries & $1(1.5)$ \\
\hline Pathological fracture of femur & $1(1.5)$ \\
\hline Chest wall swelling & $1(1.4)$ \\
\hline Total & $\mathbf{6 9}(\mathbf{1 0 0 . 0 )}$ \\
\hline Table 1. Clinicoradiological Presentations
\end{tabular}

The majority of patients presented with pulmonary mass/unresolving pneumonia 47 (68.1\%), 11 (15.9\%) presented with mediastinal widening/mass and $3(4.3 \%)$ cases presented with pleural effusion. [Table 1] 


\begin{tabular}{|c|c|}
\hline Site of lesion & N (\%) \\
\hline Right upper thorax & $18(26.0)$ \\
\hline Right lower thorax & $5(7.2)$ \\
\hline Left upper thorax & $19(27.5)$ \\
\hline Left lower thorax & $4(5.9)$ \\
\hline Mediastinum & $19(27.5)$ \\
\hline Others & $4(5.9)$ \\
\hline \multicolumn{2}{|c|}{ Total } \\
Table 2. Distribution of Site of Lesion \\
\hline
\end{tabular}

The left upper thorax and mediastinum were the most commonly involved sites $(\mathrm{n}=19,27.5 \%$ each) followed by 18 $(26 \%)$ in the right upper thorax, $5(7.2 \%)$ in the right lower thorax and 4 (5.9\%) in the left lower thorax [Table 2].

In this study, all lesions visualised by ultrasound appeared hypoechoic except in one case where it was anechoic. Out of the 69 patients who underwent USG guided aspiration, 16 patients showed pleural effusion and two patients also showed pleural thickening.

Of the 69 patients, 48 were diagnosed by FNAC as having malignancy. Fourteen were non-malignant lesions, of which one was neoplastic and 13 were inflammatory /infectious conditions ( 9 tuberculous and 4 others). The results of seven patients were unsatisfactory and no opinion could be given. Re-aspiration was done in only one case among the 48. The second aspiration was diagnosed as small cell carcinoma.

Re-aspiration was advised for the seven cases that were inconclusive or non-diagnostic. Two patients underwent the procedure. Of them, one was diagnosed to be a case of tuberculosis and the other was non-diagnostic. The remaining five patients refused the procedure or were lost to followup.

Out of the results of FNAC in 69 cases, positive diagnosis was obtained in 62 cases which are further subdivided into various groups as indicated in table 3.

\begin{tabular}{|c|c|}
\hline $\begin{array}{c}\text { Result of Positive Cytological. } \\
\text { Examination } \\
\end{array}$ & $\begin{array}{c}\text { N (\%) } \\
(62) \\
\end{array}$ \\
\hline \multicolumn{2}{|c|}{ Malignancy [n=48 (77.4\%)] } \\
\hline Poorly differentiated carcinoma & $15(31.1)$ \\
\hline Squamous cell carcinoma & $12(25.0)$ \\
\hline Adenocarcinoma & $8(16.7)$ \\
\hline Lymphoma & $8(16.7)$ \\
\hline Small cell carcinoma & $1(2.1)$ \\
\hline Plasmacytoma & $1(2.1)$ \\
\hline Small round cell tumour & $1(2.1)$ \\
\hline Pleural Mesothelioma & $1(2.1)$ \\
\hline Others & $1(2.1)$ \\
\hline \multicolumn{2}{|c|}{ Benign [n=10 (16.1\%)] } \\
\hline TB granuloma & $9(90.0)$ \\
\hline Thymoma & $1(10.0)$ \\
\hline Inflammatory/Infections & {$[\mathrm{n}=4(6.5 \%)]$} \\
\hline \multicolumn{2}{|c|}{ Table 3. FNAC Results of Positive Cases } \\
\hline
\end{tabular}

The most common type of malignant lesion was poorly differentiated carcinoma 15 (31.1\%) followed by squamous cell carcinoma 12 (25\%). The most common type of benign lesion was tuberculosis $(\mathrm{n}=9)$. [Table 3]

The overall diagnosis of benign lesion was 14 (20.3\%) and malignancy 48 (69.6\%). A histopathological diagnosis was made by correlation of biopsy obtained by bronchoscopy, pleural biopsy and surgical correlation.

\begin{tabular}{|c|c|c|c|}
\hline \multirow{2}{*}{ H.P } & \multicolumn{3}{|c|}{ FNAC (n=7) } \\
\cline { 2 - 4 } & Malignant & Unsatisfactory & Total \\
\hline Malignant & 5 & 0 & $\mathbf{5}$ \\
\hline Benign & - & 1 & $\mathbf{1}$ \\
\hline Unsatisfactory & 0 & 1 & $\mathbf{1}$ \\
\hline Total & $\mathbf{5}$ & $\mathbf{2}$ & $\mathbf{7}$ \\
\hline \multicolumn{3}{|c}{ Table 4. Histopathological Correlation } \\
\hline
\end{tabular}

All the 5 malignant lesions were correctly diagnosed by FNAC. Out of the 2 unsatisfactory cases, one was a case of tuberculosis. One case was not diagnosed by both FNAC and histopathology [Table 4].

Only one patient $(1.4 \%)$ of carcinoma bronchus with malignant effusion developed minimal pneumothorax after the procedure. Rest of the patients underwent the procedure without any complications.

\section{DISCUSSION}

In our experience, USG guided fine needle aspiration cytology of pulmonary and mediastinal masses is a safe, simple procedure and had distinct advantages over FNAC performed blindly or with fluoroscopic or CT guidance. Ultrasoundguided FNAC was significantly faster than other modalities used for guidance and yielded results in a high percentage of cases, even when the target lesion is small.

Of the 69 patients studied, $68.1 \%$ were males and $31.8 \%$ were females, showing the male preponderance with male to female ratio of 2.6:1. This is comparable to a study by Von Sonnenberg ${ }^{3}$ who in his study of 150 cases had 101 males and 44 females. Nachiappan et al 7 in his study of 100 patients also showed the male preponderance with 74 males.

VanSonnenberg 3 showed that more than half of the parenchymal lesions involved the upper lobe. In our study, 46 (66.7\%) cases involving the lung parenchyma had predominantly upper thoracic involvement. The left upper thorax is more involved $(n=19)$ compared to the right. 9 cases had lesion in the lower thorax region.

Out of the 69 cases that underwent ultrasonography, 67 cases appeared hypoechoic, one case showed mixed echogenicity (hypo-anechoic) and one case appeared anechoic. Yang $\mathrm{P}$ et $\mathrm{al}^{8}$ found that solid nodules smaller than $4 \times 4 \mathrm{~cm}$ were usually homogenous - hypoechoic with welldefined margins with an increase in echogenicity when the nodules become larger. They also found that there were no sonographically differentiating features between malignant and benign lesions. Sheth $\mathrm{S}$ et $\mathrm{al}^{4}$ found that small peripheral masses are hypoechoic with an echogenic interface between the lesion and the surrounding aerated lung. Chang-Jen Yu et $\mathrm{al}^{5}$ found that the echogenicity and the internal echo of most tumours are hypoechoic and homogenous in spite of different histologic findings. They also found that all benign tumours were hypoechoic, and most of them were homogenous in internal echo, except thymomas which showed heterogenous echogenicity.

Of the 69 patients in our study, 16 showed pleural effusion and two patients showed pleural thickening. Presence of pleural effusion is helpful as an acoustic window in identifying the underlying mass and guiding FNAC. Ikezoe $\mathrm{J}$ et $\mathrm{al}^{9}$ in their study stated that USG guided FNAC is highly suitable for peripheral lung tumours with adjacent pleural effusion. Hsu W et al ${ }^{10}$ in their study, concluded that they recommend the use of ultrasonography and ultrasonography-guided needle 
biopsy (UGNB) to detect and diagnose pleural masses, especially when malignant pleural effusions are highly suspected and underdiagnosed.

Of the lesions diagnosed as malignant, poorly differentiated carcinoma accounted for $31.2 \%$ cases, squamous cell carcinoma $25 \%$ cases and adenocarcinoma $16.3 \%$ of the cases. In this study, lymphoma of the mediastinum was also diagnosed (16.3\%). In the series of 116 cases studied by Khouri et al,11 $10.3 \%$ cases were diagnosed as lymphomas. Yu C et al ${ }^{5}$ found that correct histologic diagnosis with ultrasound-guided aspiration biopsy (UGAB) alone is lower in thymoma (55\%) and lymphoma (30\%), but higher in lung cancer (67\%) and metastatic cancer (78\%).

Of the lesions diagnosed as benign, tuberculosis accounted for $64.2 \%$ cases, nonspecific inflammation for $28.5 \%$ cases and thymoma for $7.1 \%$ cases. In cases diagnosed as pulmonary tuberculosis, the FNAC results correlated with the subsequent clinical course and improvement on antitubercular drugs. Ikezoe J et $\mathrm{al}^{12}$ found that $39.9 \%$ of the cases were benign lesions in their study of USG guided needle biopsy for diagnosis of thoracic lesions.

It is traditionally considered that lesions greater than $2 \mathrm{~cm}$ in diameter will render better results on fibreoptic bronchoscopy as compared to FNAC, while FNA should be the choice for lesions less than $2 \mathrm{~cm}$. In our study, all lesions were greater than $2 \mathrm{~cm}$ and the diagnosis was made by fine needle aspiration. Rio $\mathrm{F}$ et al $^{13}$ in their study had $60.7 \%$ lesions greater than $2 \mathrm{~cm}$ for CT guided FNAC in bronchoscopic negative cases. Besides the limitation related to size, the efficacy of fibreoptic bronchoscopy depends on the nature of the lesion and its relation to bronchial tree. Borgeskov S. et al ${ }^{14}$ concluded that peripheral endobronchial tumour cannot be visualised and FNA may give a diagnostic accuracy of $60 \%$ $80 \%$.

Reaspiration was done in $13 \%$ cases by Khouri et al ${ }^{11}$ while $68 \%$ of cases showed definite diagnosis and in $4 \%$ patients, the nature of the lung pathology was not helpful in elucidating the nature of the lesion either because the patient was lost to followup or because of refusal of additional workup.

The cytological diagnosis could be correlated with histopathological diagnosis in $7(10.1 \%)$ cases. The histopathological correlation was done on the basis of bronchoscopic biopsy, surgery, and pleural biopsy in these seven cases. Nachiappan et al 7 had $22 \%$ correlation of cytology with histopathology and about $80 \%$ accuracy was found for malignant lesions. Arakawa et $\mathrm{al}^{15}$ had $33 \%$ correlation with histopathology.

Of the seven cases correlated histopathologically, an accuracy of $100 \%$ was obtained for malignant lesions. Two cases with unsatisfactory FNAC reports were also included wherein one case was diagnosed to be tuberculosis and the other remained inconclusive. This result compares well with the experience of Simpson et al ${ }^{16}$ who obtained an accuracy of $80.9 \%$ and Nachiappan et al ${ }^{7}$ who also achieved an accuracy of $80 \%$ for malignant lesions.

In 62 cases, the FNAC diagnosis could not be correlated with histopathological diagnosis. However, the clinical behaviour of the patients and followup helped in the confirmation of diagnosis.

The most common complication reported in literature was pneumothorax. Reported rates range from $0 \%$ as studied by Karl Wernecke et al ${ }^{6}$ to $49 \%$ by Berquist et al. ${ }^{17}$
In our series, 1 case $(1.4 \%)$ showed minimal pneumothorax in post-procedural chest x-ray which resolved by itself. This could be explained by a meticulous approach to obtain a sample.

Nachiappan et al7 in their study of FNAC without any guidance reported an accuracy of $80 \%$, a complication rate of $3 \%$ (pneumothorax) and cellular yield of $87 \%$. In our study, the overall positive cellular yield is $88.6 \%$ with only one case of pneumothorax $(1.4 \%)$ and accuracy of $100 \%$ in malignant lesions when compared with histopathology reports.

\section{CONCLUSION}

Ultrasonography-guided Fine Needle Aspiration Cytology (FNAC) is a technically simple, rapid, cost-effective and accurate procedure for evaluating malignant and benign lesions of lung and mediastinum, without the danger of exposure to ionising radiation as in CT. It should be considered before CT guided FNAC and thoracotomy and in many cases, it might even be performed before fibreoptic bronchoscopy evaluation. It may even be better to do USG guided FNAC for all intrathoracic mass lesions as a screening procedure. It has the multiplanar capability which allows the use of an oblique angled approach if needed. In establishing the diagnosis of lung lesion, guided FNAC plays a very significant role in the rapidity of triggering management decisions. It also boasts of a low rate of occurrence of complications. The popularity of FNAC may be short-lived if it is not performed with the proper level of expertise and with a broad scope of identifying benign as well malignant lesions. Skill and experience are the most important parameters for achieving satisfactory results in the demonstration of benign and malignant lesions. The other very important parameter is the interest and experience of the pathologist or cytopathologist. ${ }^{7}$

\section{REFERENCES}

1. Westcott JL. Direct percutaneous needle aspiration of localized pulmonary lesions: result in 422 patients. Radiology 1980;137(1 Pt 1):31-5.

2. Perlmutt LM, Johnston WW, Dunnick NR. Percutaneous transthoracic needle aspiration: a review. American Journal of Roentgenology 1989;152(3):451-5.

3. VanSonnenberg E, Casola G, Ho M, et al. Difficult thoracic lesions: CT-guided biopsy experience in 150 cases. Radiology 1988;167(2):457-61.

4. Sheth S, Hamper UM, Stanley DB, et al. US Guidance for Thoracic Biopsy: A Valuable Alternative to CT. Radiology. 1999;210(3):721-6.

5. Yu CJ, Yang PC, Chang DB, et al. Evaluation of ultrasonically guided biopsies of mediastinal masses. Chest 1991;100(2):399-405.

6. Wernecke K, Vassallo P, Peters PE, et al. Mediastinal tumors: biopsy under US guidance. Radiology 1989;172(2):473-6.

7. Nachiappan M, Banerjee A, Rao SK, et al. Role of fine needle aspiration cytology in the management of thoracic lesions. ANZ J Surg 1990;60(1):31-33.

8. Yang PC, Luh KT, Sheu JC, et al. Peripheral pulmonary lesions: ultrasonography and ultrasonically guided aspiration biopsy Radiology 1985;155(2):451-6. 
9. Ikezoe J, Morimoto S, Arisawa J, et al. Percutaneous biopsy of thoracic lesions: value of sonography for needle guidance. American Journal of Roentgenology 1990;154(6):1181-5.

10. Hsu W, Chiang CD, Hsu JY, et al. Value of ultrasonically guided needle biopsy of pleural masses: an under-utilized technique. J Clin Ultrasound 1997;25(3):119-25.

11. Khouri N, Stitik F, Erozan YS, et al. Transthoracic needle aspiration biopsy of benign and malignant lung lesions. American Journal of Roentgenology 1985;144(2):281-8.

12. Ikezoe J, Sone S, Higashihara T, et al. Sonographically guided needle biopsy for diagnosis of thoracic lesions. American Journal of Roentgenology 1984;143(2):229-34.

13. Rio GF, Lobato DS, Pino JM, et al. Value oF CT-guided fine needle aspiration in solitary pulmonary nodules with negative fiberoptic bronchoscopy. Acta Radiologica 1994; 35(5):478-80.
14. Borgeskov S, Francis D. A comparison between fineneedle biopsy and fiberoptic bronchoscopy in patients with lung lesions. Thorax 1974;29(3):352-4.

15. Arakawa H, Nakajima Y, Kurihara Y, et al. CT-guided transthoracic needle biopsy: a comparison between automated biopsy gun and fine needle aspiration. Clinical Radiology 1996;51(7):503-6.

16. Simpson RW, Johnson DA, Wold LE, et al. Transthoracic needle aspiration biopsy. Review of 233 cases. Acta Cytol 1988;32(1):101-4.

17. Berquist TH, Bailey PB, Cortese DA, et al. Transthoracic needle biopsy: accuracy and complications in relation to location and type of lesion. Mayo Clin Proc 1980;55(8): 475-81. 